\title{
Exploring the Relations between Business Intelligence and the Learning Organization
}

\author{
Laurentiu COROBAN ${ }^{1}$ \\ Alexandru Adrian GAVRILA ${ }^{2}$
}

\begin{abstract}
In this paper we try to study and analyze how BI has an influence over the learning organization. Corporations globally are struggling to keep pace in the "information economy" and the rapid growth of the Internet and related technologies is strengthening demand for data management strategies. Also we present some of the characteristics of the leading tool for BI from Microsoft, Power BI.

Business intelligence (BI) has and emerged as a powerful tool that allows businesses to capture, analyze, interpret, and report on data -thus creating valuable businesses information to for the enterprise. Massive investments in ERP systems over the past decade have resulted in huge data storage mechanisms.

In addition, the deployment of electronic commerce strategies on the Internet results in large volumes of data, such as click-stream information. Learning organizations need to take advantage of the BI provided and use it to increase their competitiveness in the industry.
\end{abstract}

Keywords: business intelligence, learning organization, enterprise resource planning

JEL classification: M12, M14, E50.

DOI: $10.24818 /$ RMCI.2019.2.198

\section{Introduction}

Business intelligence is the environment that supports analysis of data from any source (internal or external) to provide valuable information for making operating, tactical, or strategic decisions. (Cody et. al 2002)

The concepts of business intelligence are not entirely new and have emerged from data-mining techniques, decision support systems, data warehousing, knowledge management, and other business tools that have been used for many years. BI differs from these other tools in that it is a completely integrated approach to data management and has been made possible by advances in technology such as the internet, ERP, and database systems.

Business intelligence applications can be closely related to CRM strategies, and in many instances the two go hand in hand. Business intelligence can be used any time that an organization wishes to better understand its data to improve decision-making.

\footnotetext{
${ }^{1}$ Laurentiu Coroban, Universitatea de Vest din Timisoara, dorucoroban @ yahoo.com

${ }^{2}$ Alexandru Adrian Gavrila, Bucharest University of Economic Studies, galex@ase.ro
}

$198 \quad$ Review of International Comparative Management $\quad$ Volume 20, Issue 2, May 2019




\section{Content}

Business intelligence has evolved from previous data management systems such as data warehousing. As businesses struggle to gain a competitive advantage, BI offers the potential to improve decision-making and improve profitability. However, many organizations have recently undergone massive investments in ERP systems which promised an integrated data environment - leaving many wondering why BI is even necessary. (Wang, Noe 2010)

Enterprise resource planning (ERP) systems promised businesses a single data environment to capture transaction data and integrate all parts of the business. ERP implementations have ranged widely in their successes but in the reporting and analysis area have lacked the ability to satisfy users. A number of important reasons exist as to why ERP systems are not suitable for data analysis, reporting, and decision support - the most important being that ERP was designed as a transaction - based processing system. (Gralund, Malmi 2002)

According to a recent report from Gartner (Howson C. et all 2019), for 12 consecutive years (till present - 2019), Microsoft was a leader in analytics and business intelligence.

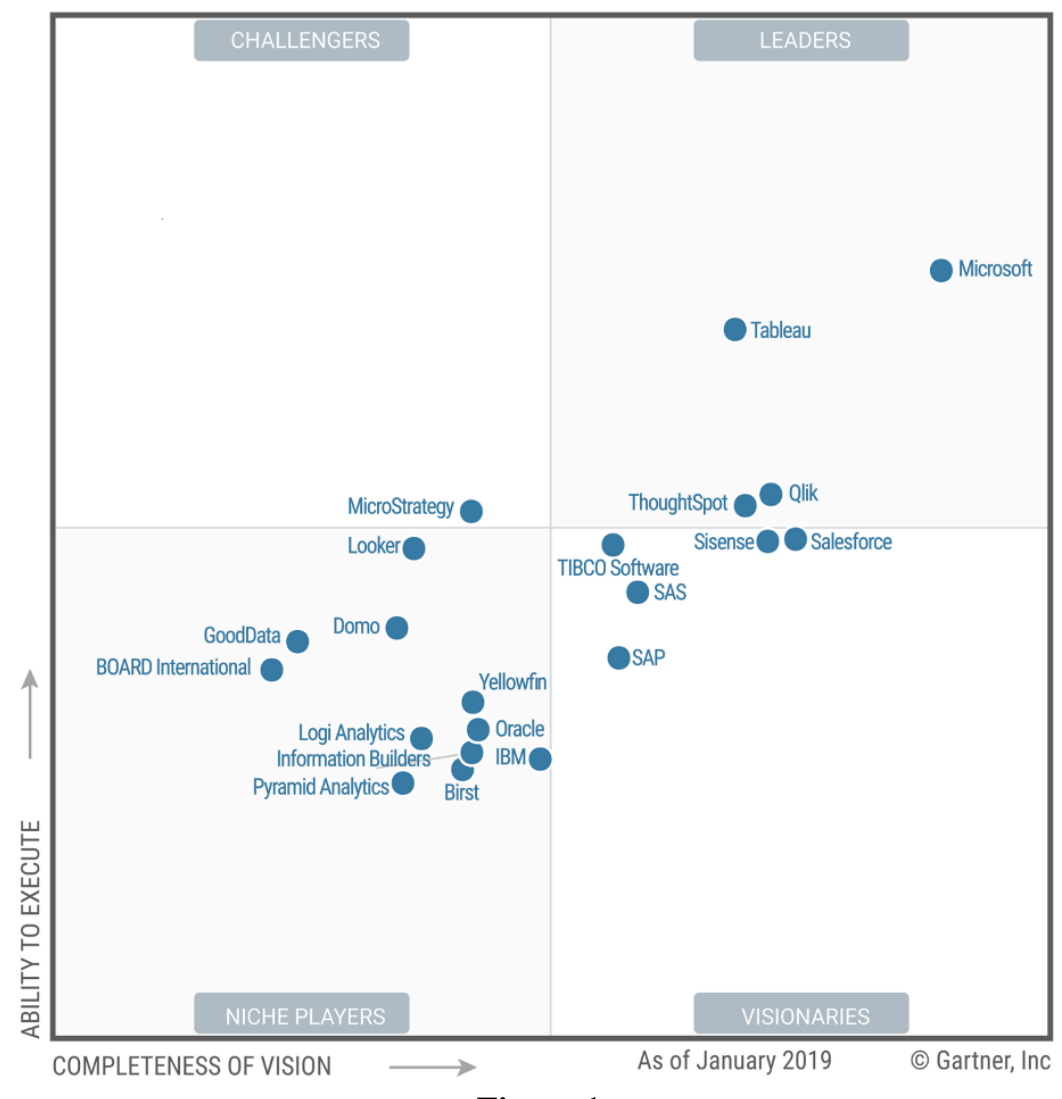

Figure 1

Source: Gartner (February 2019) 
In this report, Gartner assess the features and capabilities that differentiate the various products in this market and shows how the product vision, the experience of sales and the user experience of Microsoft tools contributed to high levels of customer satisfaction and helped position Microsoft as a Magic Quadrant Leader in the field of analytics and business intelligence platforms. The main tool created by Microsoft for this category of software is Power BI, which is part of Office365's Enterprise offerings.

Power BI is a collection of software services, apps, and connectors that have the ability to work together to turn many various unrelated sources of data into coherent, visually immersive, and interactive insights. Your data may be in virtually any form: an Excel spreadsheet, an Access or SQL Server database or hybrid repositories, and a collection of hybrid data repositories. Power BI allows you to easily connect to data sources, view and also discover what's most important and share with anyone or anyone you want.

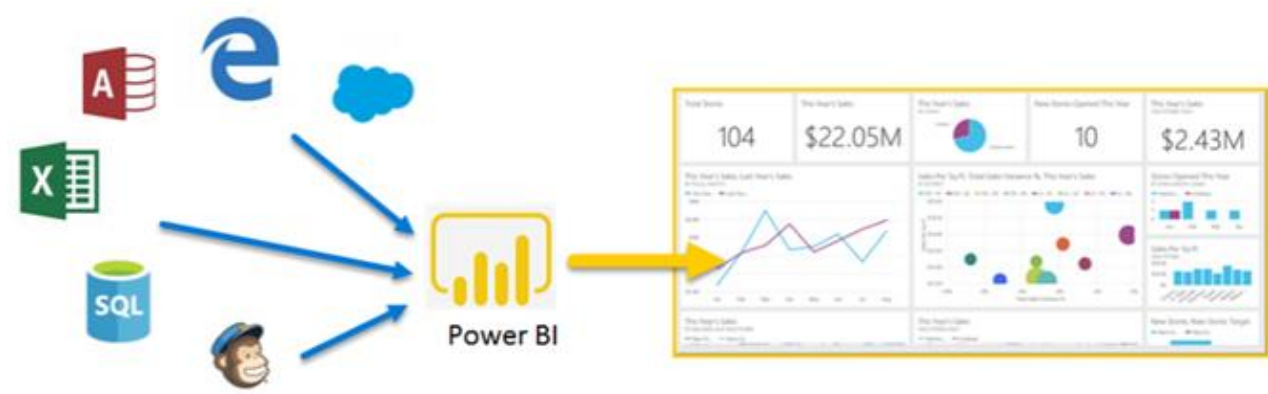

Figure 2

Source: Microsoft.com (2018)

Power BI can be simple and fast to use, capable of creating quick insights from an Excel spreadsheet or another data source like a local database. But Power $\mathrm{BI}$ is also robust and enterprise-grade, ready for extensive modeling and real-time analytics, as well as custom development with simple scripting language. It can create reports and serve as a visualization tool, and also can help as the analytics and decision engine for group projects, divisions, or entire corporations.

It marks the latest development in two important and ongoing trends in business intelligence. The first is the move toward self-service, which means that you'll be able to pull up the metrics you need on your own, without having to involve a BI expert or someone from IT. The second is the growing reach of Big Data, which involves the collection and processing of massive amounts of information. Very often Big Data analyses are performed on information from different sources with various purposes that don't have anything to do with providing business insights.

Even if Microsoft has made steps for long time in the BI area with SQL Server Analysis Service (SSAS), he failed to deliver client or presentation layer technologies such as Online Analytical Processing (OLAP). Power BI is designed to 
complete in this way the offer in BI software. Here are some of the advantages and the disadvantages of Microsoft Power BI.

\section{Power BI Advantages:}

$\checkmark$ Power BI a inclus inițial instrumente precum Power Query pentru transformare și extragere, Power Pivot pentru a modela și analiza și Power View și Map pentru vizualizarea datelor. Power BI Designer consolidează instrumentele separate într-o aplicație all-in-one și acest lucru poate anula, poate exclude dependențele de alte instrumente Microsoft cum ar fi Excel sau Office.

$\checkmark$ Analysts can now use an easy business intelligence tool to extract source data, create a dataset, transform or manipulate the data, visualize the data and publish the resulting reports and dashboards without requiring IT involvement.

$\checkmark$ The dashboard visualizations are best in class and continually updated from the big community of users. Interactive geo-map visualizations are empowered by Bing Maps.

$\checkmark$ The DAX (Data Analysis Expressions) scripting language is a relatively simple construct used to create calculated columns and measures. It's very similar to Excel, although while Excel is cell based, DAX is column based. data.

$\checkmark$ There are very much sources from whom Power BI can connect and query

$\checkmark$ Power BI is updated very frequently, about once a month.

\section{Power BI Disadvantages:}

$\checkmark$ Even if the integration with MS Dynamics CRM is evolving, there still remain few limitations, among which we can name security restrictions, because security is applied to the desktop tool and only then the security granted to the person who creates the data model is distributed, extended to all data consumers on PowerBI.com, but unless the creator has specified other security permissions.

$\checkmark$ Reports generated by Power BI and dashboards can not accept or fail to transmit parameters for a user, account, or other entity, so it is impossible to create body-specific dashboards, such as a dashboard for a account, an opportunity, or a case, a campaign. Instead, all dashboards are limited to aggregate impressions of entity data.

$\checkmark$ Not all data sources accept real-time (near) connections in Power BI reports and dashboards. Also, using such real-time connections limits the Power BI access to a single data source, cancels Edit View and removes some very interesting key capabilities.

$\checkmark$ There is no limitation or restriction on the data rows that you can import into Power BI at the moment. However, Power BI offers 2 licenses, Power BI (free of charge) and Power BI Pro, with different data capacity limits: Free users are those with a maximum data capacity of 1 GB. Pro Users for Power BI Pro are users with a maximum capacity of $10 \mathrm{~GB}$. 
What we believe is relevant and important is how can we use this vast amount of data for achieving our organizational goals? How knowledge is involved in it?

One of the main characteristics of knowledge is that it is highly organized. This can be demonstrated quite simply. Even though we have millions of facts and pieces of information stored in memory, we are able to answer questions about that information very rapidly. For example, see how quickly you can name the president of your country, a vegetable beginning with $\mathrm{C}$ and the capital of France. In most cases it is likely that you could answer such questions in just a fraction of a second. Such fast response would seem highly unlikely if semantic memory were not organized in some way.

Exactly how knowledge is organized and used in memory has been a major debate in cognitive science. One of the most influential approaches has been to assume that knowledge is organized as some form of network. Concepts are arranged so that those that have something in common are linked in some way. For example, the names of countries and their capitals would be stored in close connection to each other rather than distributed randomly. Semantic networks (Collins and Loftus, 1975) are represented as nodes and links. Nodes correspond to objects, such as cat, dog, horse, or classes of objects, such as animals, whereas links correspond to the relationships between the objects. These can be simple links like 'a cat is an animal' or 'a dog can bite'.

Another theory views knowledge as consisting of numerous schemes or diagrammatic representation. Essentially, a schema is a network of general knowledge based on previous experience. Its function is to facilitate our understanding of commonplace events. In turn, this is what enables us to behave appropriately in different situations. The most well-cited example of a schema is Schank and Abelson's (1977) restaurant script. The underlying assumption is that people develop a script by repeatedly carrying out the same set of actions for a given setting.

Similarly, when we interact with computers, diagrammatic representation can be viewed as guiding our behavior. The significance of diagrammatic representation is that they allow us to carry out everyday activities with minimum effort and to capitalize on the regularities of events and situations. When confronted with new but similar situations, they help us to know how to behave appropriately and what to look for. (Davenport et. al 2004)

These human behaviors can be extrapolated to the organizations as well. To view the organizations as a human extension is something that can be studied more thoroughly in the future.

Digital transformation is at the top of the global development strategy priorities. The current technological context is defined by increasing volumes of data to be processed and organizational digitization. Therefore, implementing Business Intelligence (BI) and Knowledge Management (KM) solutions will become a must for organizations that adhere to the concept of digital transformation and want to automate their work processes. 
According to Wang, business intelligence and knowledge management are two independent information systems domains (Wang and Wang, 2008). Herschel (2005) argue that knowledge management can also be used to support decision making processes by providing new ways for sharing knowledge in organizations. Knowledge management techniques, in the context of BI, can be seen as facilitator for managing, storing, visualizing, analyzing, and giving access to a great amount of data. Technology, as the foundation of BI, needs to provide an integrated view of internal and external data. A wide range of intelligent technologies (for example online analytical processing, data mining, cloud computing) are used in developing of a BI system.

Competitive advantages are conditions that allow a company to produce goods or services of equal value at a lower price or in a more desirable fashion. These are the conditions that allow the productive entity to generate far more sales or higher margins than its market competitors. Organizations must develop and enhance core competencies in order to establish and sustain their competitive advantage (Prahalad et al., 1990). Then how can we approach this cost element of the learning organization? What about the costs that are related to this learning approach?

According to Lado and Zhang (1998) the cost of learning is difficult to assess but knowing how important costs are for the business, it is useful to consider options that could reduce these learning costs. To achieve the benefits of formalized training, business may find it advantageous to hire a consultant or purchase pre-packaged training. Businesses should also examine the feasibility of developing a consortium of businesses that could all use the same training.

Why not take advantage of this commonality and work together to identify training needs and share in the cost of developing or purchasing relevant training? Sharing the cost among companies reduces the cost per unit for each. If this shared development expense can be done for e-learning, it can also be done for any type of training development, thus becoming affordable for businesses (Smith 2003). Also, given the increasing number of businesses, the expense could be shared among more, making the cost of development even less.

E-learning is now an option for the business. Numerous businesses are providing a template for developing online learning. This way, the small business gets affordable training that can be tailored to its needs. There are a number of elearning opportunities now available. What if some training companies allows trainers from other companies to use their authoring tools to build training programs? No cost is charged until employees begin to take the course, and then the cost is on a per-employee basis. Some companies can be even more adventuresome and develop an online learning university.

Businesses often belong to industry-specific associations that can provide a venue for discussing this idea to determine the level of interest. 


\section{Conclusion}

In today's economy organizations are under high pressure to gain competitive advantage in order to reach business goals and to survive on the competitive markets. Consequently, it is critical to make in time decisions based on reliable and accurate data.

Interaction with customers who nowadays are using all possible communication models, is relevant for our organization. We need quick and timely answers based on sound business decisions. Business decisions must be taken on the basis of timely and reliable information.

To achieve a constant process inside the organization we must establish a continuous learning process based on knowledge.

\section{References}

Cody, W.F. et al. (2002). The Integration of Business Intelligence and Knowledge Management, IBM Systems Journal, (41)4

Davenport, T.H., Harris, J.G. and Cantrell S. (2004). Enterprise systems and ongoing process change, Business Process Management Journal, 10(1)

Granlund, M. and Malmi, T. (2002). Moderate impact of ERPs on management accounting: a lag or permanent outcome? Management Accounting Research, 13(3)

Herschel RT, Jones NE (2005). Knowledge management and business intelligence: the importance of integration. J. Knowledge Management. 9(4).

Howson C., Richardson J., Sallam R., Kronz A. (2019). Gartner Magic Quadrant for Analytics and Business Intelligence Platforms

Lado, A., and Zhang, M. J. (1998), Expert Systems, Knowledge Development and Utilization, and Sustained Competitive Advantage: A Resource Based Model, Journal of Management, 24(4)

MacDougall P. (2001), Companies that dare to share information are cashing in on new opportunities, Information Week

Prahalad CK, Hamel G, June MY (1990). The Core Competence of the Corporation. Harvard Bus. Rev. 68(3).

Smith, P. J. (2003). Workplace learning and flexible delivery. Review of Educational Research, 73

Wang S., Noe R.A., (2010) Knowledge Sharing: A Review and Directions for Future Research. Human Resource Management Review, 20

Wang H, Wang S (2008). A knowledge management approach to data mining process for business intelligence. Ind. Manage. Data Syst. 108(5).

Wu J., (2000). What is this Data? End user presentation of Meta Data. DM Review 